\title{
Alta-Assistida de usuários de um hospital psiquiátrico: \\ uma proposta em análise
}

| 'Magda Dimenstein, íntia Guedes Bezerra |

Resumo: Um dos obstáculos atuais à Reforma

Psiquiátrica é a ausência de uma rede assistencial ágil, flexível e resolutiva. A proposta de saída dos usuários do hospital de forma planejada e assistida é uma estratégia fundamental no processo de desinstitucionalização, no sentido de evitar o tão acentuado fenômeno da reinternação. Tal situação está relacionada à falta de uma rede de atenção extra-hospitalar, bem como de suporte e acompanhamento do usuário por parte da equipe técnica em parceria com as famílias. Com base nisso, realizou-se uma investigação em um hospital psiquiátrico do município de Natal, visando a avaliar o processo de implantação e o funcionamento do Projeto de Alta-Assistida atualmente em curso nessa instituição. Este trabalho objetiva discutir os resultados dessa investigação.

> Palavras-chave: saúde mental; reforma psiquiátrica; hospital psiquiátrico; alta-assistida; reinserção social.

\footnotetext{
${ }^{1}$ Doutora em Saúde Mental pela Universidade Federal do Rio de Janeiro; professora no Departamento de Psicologia da Universidade Federal do Rio Grande do Norte; pesquisadora do CNPq. Endereço eletrônico: magda@ufrnet.br.

2 Psicóloga, mestranda do Programa de Pós-Graduação em Psicologia da UFRN. Endereço eletrônico: cintiagbezerra@yahoo.com.br.
} 


\section{O Projeto de Alta Assistida do Hospital Psiquiátrico Dr. João Machado: contextualizando uma proposta}

Esta investigação ${ }^{1}$ foi realizada no Hospital Psiquiátrico Dr. João Machado/HJM, hospital de referência na assistência psiquiátrica da cidade de Natal/RN vinculado à Secretaria do Estado de Saúde do Rio Grande do Norte, sendo a esfera administrativa estadual e a gestão municipal (BRASIL/CNES, 2009). A instituição foi inaugurada no ano de 1957 e está classificada como de média complexidade no Sistema Único de Saúde (SUS), ou seja, oferece atendimento especializado à população e utiliza recursos tecnológicos para diagnóstico e tratamento (BRASIL, 2006). Atualmente, disponibiliza 142 leitos para internação, distribuídos entre enfermarias masculinas e femininas e intercorrências masculinas e femininas no pronto-socorro.

A seguir, destacamos alguns dados da atual configuração da atenção à saúde mental no estado.

Tabela 1 - Rede CAPS por tipo e indicador CAPS por 100.000 habitantes, Brasil

\begin{tabular}{ccccccccc} 
UF & População & CAPS I & CAPS II & CAPS III & CAPSi & CAPSad & Total & $\begin{array}{c}\text { Indicador CAPS } \\
/ 100.000 \text { hab }\end{array}$ \\
\hline RN & $\begin{array}{c}3.106 .430 \\
\text { Brasil }\end{array} \begin{array}{c}189.612 .81 \\
4\end{array}$ & 9 & 10 & 0 & 2 & 5 & 26 & 0,69 \\
\hline & 618 & 382 & 39 & 101 & 186 & 1326 & 0,55 \\
\hline
\end{tabular}

Fonte: Tabela construída com base nos dados da Coordenação Nacional de Saúde Mental, Álcool e Outras Drogas/DAPES/SAS. Instituto Brasileiro de Geografia e Estatística, Estimativa Populacional 2008 (BRASIL, 2009, p. 20).

Em relação à distribuição de leitos psiquiátricos SUS, o RN assume a quinta posição no ranking nacional. Com uma população de 3.013.740 habitantes, dispóe de cinco hospitais com 747 leitos psiquiátricos, resultando numa percentagem de 1,98 leitos SUS e uma taxa de 0,25 leitos por mil habitantes (BRASIL, 2009b). O Rio Grande do Norte conta com apenas um Serviço Residencial Terapêutico, implantado em 2005, com seis moradores e dois em processo de implantação 
(BRASIL, 2009c). O Programa De Volta para Casa, instituído pela Lei no 10.708/ 03, possui cinco beneficiários (BRASIL, 2009d).

O HJM foi construído nos moldes da psiquiatria asilar, modelo característico da época, mas na década de 1990 passou a sofrer influência das lutas sociais já iniciadas pelo movimento da reforma sanitária brasileira. Hoje, o hospital está inserido no processo de reforma psiquiátrica e de questionamento de suas práticas, buscando participar das discussões acerca das novas formas de atenção à saúde mental em curso no país.

A Reforma Psiquiátrica pode ser compreendida como uma proposta ampla de mudança no atendimento público em saúde mental, garantindo o acesso da população aos serviços, além do respeito aos direitos e à liberdade dos sujeitos portadores de transtorno mental. Propõe a substituição do tratamento baseado no isolamento para alternativas que valorizam o convívio familiar e comunitário, tendo como principal estratégia a reabilitação psicossocial. Dessa forma, visa a uma progressiva substituição dos hospitais psiquiátricos por acompanhamentos realizados nos CAPS, nas residências terapêuticas, nos ambulatórios, nos hospitais gerais e nos centros de convivência, sendo as internações, quando necessárias, realizadas no CAPS-24horas ou nos hospitais gerais (DELGADO, 2001).

Em conformidade com as proposições da reforma psiquiátrica que visam a diminuir o número de leitos e o tempo de internação dos pacientes, o HJM vem executando ações como: promoção de atividades de ressocialização, realização de passeios externos, apoio e preparação de pacientes crônicos residentes para morarem em residência terapêutica, encaminhamento para serviços substitutivos e, dentre outras, a proposta e efetivação do Projeto de Alta-Assistida (AA). O projeto objetiva reverter o processo de exclusão social que os ex-internos enfrentam, possibilitando um trabalho não só junto ao paciente, como também a seus familiares. Nesse sentido, considera-se que o sofrimento enfrentado pelas famílias, fruto de um sentimento de culpabilidade, vergonha e vitimização, culmina na não-aceitação do ex-interno, por ser visto como incurável, irrecuperável e imprevisível (FIORATI, 2006). Esse fato precisa ser cuidado através de ações no território do paciente, da ajuda aos familiares, possibilitando um futuro sustentável fora da instituição.

No ano de 2005, alguns profissionais do HJM, preocupados com o alto índice de reinternação dos usuários, passaram a realizar uma prática diferenciada: acompanhar o paciente no seu momento de alta hospitalar, na tentativa de assegurar 
um tratamento na comunidade do paciente e evitar a reinternação. Inicialmente eram práticas isoladas, sobretudo na enfermaria-escola do hospital, das quais participavam a psicóloga, a assistente social, a enfermeira, o médico, os residentes e estagiários. Tendo em vista o sucesso em alguns casos, a ideia foi levada para a reunião técnica que ocorria quinzenalmente. Na época, a diretora técnica acatou a proposta e, juntamente com os outros profissionais, criou um projeto com o intuito de oficializar e institucionalizar o que já vinha ocorrendo. Esperava-se que os pacientes contemplados pelo projeto não sofressem tantas reinternações quanto aqueles que recebiam alta, mas não passavam por tal acompanhamento.

O projeto de AA objetiva: 1) promover um contato com o paciente e sua família após a alta, orientando a respeito da importância da medicação e do comprometimento com o tratamento; e 2) direcionar o acompanhamento do portador de transtorno mental para alguma unidade de saúde ou CAPS que exista na região de seu domicílio, com a finalidade de estabelecer comprometimento do gestor de saúde do município com o tratamento do paciente assistido. Em outras palavras, busca-se articular e assegurar um tratamento no espaço extramuros, evitar reinternação e inserir o paciente na sua comunidade, em conformidade com as diretrizes da reforma psiquiátrica e, portanto, com a lógica atual da atenção psicossocial ao portador de transtorno mental.

$\mathrm{O}$ projeto de AA tem como proposta de funcionamento as seguintes etapas: inicialmente, é feito o trabalho da alta médica na enfermaria e mantido um prévio contato com familiares do paciente inserido no projeto e gestores dos serviços de saúde e/ou representantes do município ou bairro do paciente que possam receber a equipe. Dependendo da complexidade do caso, poderá haver a visita ao domicílio do paciente e/ou município, ou apenas um contato telefônico. Na visita domiciliar, devem ser realizados apoio e suporte psicológico aos familiares, esclarecimento da importância da continuidade do tratamento, entrega de medicamentos, indicação aos serviços substitutivos e respostas às dúvidas e questionamentos que possam surgir. Junto aos gestores, geralmente podem ser levadas informações a respeito do número de pacientes do município que são internados no HJM e indicações sobre como implantar um serviço substitutivo, caso seja interesse do município, ou então, para onde encaminhar a demanda local por este tipo de serviço. Além disso, como já dito acima, seria feito contato com Programa Saúde da Família (PSF) e/ou Programa de Agente Comunitário de Saúde (PACS) correspondente. 
No início, ficou acordado nas reuniões técnicas que a equipe multidisciplinar composta de médico psiquiatra, enfermeiro, psicólogo, assistente social, terapeuta ocupacional, nutricionista e técnicos de enfermagem - de cada enfermaria se responsabilizaria por realizar as altas assistidas de seus pacientes, ficando o hospital e a Secretaria de Saúde do estado com o compromisso de disponibilizar transporte e diárias para os casos de usuários do interior. Além disso, nas reuniões os profissionais deveriam relatar os casos que estão acompanhando, para que se pudesse refletir em conjunto sobre a situação em questão.

Foi criado um livro para registro das altas assistidas realizadas, com o objetivo de ter um controle do que estava sendo feito, bem como ser utilizado em futuras pesquisas sobre o projeto. Esse livro fica arquivado no setor de serviço social e deveria ser utilizado por qualquer profissional da equipe, mas em geral apenas as assistentes sociais o fazem. As ações desenvolvidas deveriam estar registradas nesse livro e também nos prontuários dos pacientes.

O projeto foi oficializado em março de 2006 e desde então não passou por nenhuma avaliação acerca do que já foi realizado e dos efeitos produzidos. Apesar de apenas dois casos dos 73 pacientes registrados no projeto terem se reinternado, aponta-se um alto percentual de reinternação, pois o número de registros é bem inferior ao número de casos que passaram pelo projeto. A despeito dos esforços por parte da equipe técnica e da direção do HJM, ainda se averigua um quantitativo enorme de reinternações hospitalares, indicando frágil articulação com os serviços da comunidade, bem como ausência de equipamentos na rede de atenção à saúde mental. No período de janeiro de 2007 a julho de 2008, o HJM efetuou um total de 2.516 internações. Muitas dessas internações correspondem, na verdade, a reinternaçōes. Através do SAME (Serviço de Assistência Médica e Estatística) do HJM, verificou-se que há grande número de reincidências registradas no ano de 2007 e no primeiro semestre do ano de 2008 no HJM, o qual chega a ultrapassar a metade do número de internaçoes, ou seja, 62,77\% e 60,38\%, respectivamente.

Essas constantes reinternações, como colocado acima, são em geral decorrentes da inexistência ou ineficácia de uma rede de suporte e atenção extra-hospitalar ao paciente, fato bastante evidente em Natal/RN. Não se dispõe, no estado, de CAPS III, leitos em hospitais gerais e de emergência, centros de convivência e cultura, casas de passagem e muito menos de uma articulação eficaz com a rede de serviços substitutivos e de atenção básica de saúde. Em outras palavras, não são oferecidos 
serviços que deem suporte à crise de forma eficaz, fazendo com que o hospital psiquiátrico se mantenha como centro de captação desses usuários. Além disso, as reinternações decorrem da ausência de tratamento e esclarecimento sobre a necessidade de acompanhamento continuado, bem como de conflitos familiares, comorbidade com drogas, por determinação judicial, tratamento e uso irregular de medicação, desinformação sobre os transtornos mentais e problemas decorrentes do imaginário, que associa o portador de transtorno mental a periculosidade, marginalidade e agressividade, gerando intolerância e violência com o sujeito em sofrimento mental.

Considera-se que a implantação desse projeto precisaria ser avaliada, a fim de orientar o trabalho que vinha sendo desenvolvido e abrir possibilidades de inclusão de novas perspectivas de atenção e cuidado, pois o projeto de AA tem a potencialidade de ser uma ferramenta fundamental no processo de mudança das práticas em saúde mental. Buscou-se, então, realizar discussão sobre o processo de implantação e funcionamento da proposta. Para tanto, recorreu-se ao livro de registro do setor de serviço social e aos prontuários de alguns pacientes; foram realizadas entrevistas com profissionais que realizaram altas-assistidas e participaram da criação do projeto em torno dos seguintes aspectos: o que foi feito desde seu surgimento? O que está sendo realizado atualmente? Quais as dificuldades e os êxitos encontrados?

Este trabalho objetiva apresentar e discutir os resultados dessa investigação e, quiçá, contribuir em dois sentidos: com a reversão do atendimento psiquiátrico realizado em grandes hospitais para os serviços substitutivos e a diminuição das reinternações no contexto local.

\section{A proposta metodológica}

A investigação se iniciou com a leitura do Projeto de Alta-Assistida, a fim de possibilitar maior apropriação da proposta e seus objetivos. Em seguida, foram mapeados os registros dos casos já encaminhados desde o início do projeto e uma análise atenta dos registros que ficam sob a responsabilidade do setor de Serviço Social. Desse livro de registros foram obtidas as seguintes informações, que ajudaram a traçar o perfil dos pacientes: nome do paciente; enfermaria em que estava internado; contato e encaminhamento realizados; nome da pessoa de referência, familiar ou não; receptividade dos familiares, bem como do gestor de saúde, caso o usuário seja de outro município diferente da capital. 
Inicialmente, a proposta era investigar os prontuários de todos os 73 pacientes inseridos no projeto, mas esse procedimento foi impossibilitado em virtude da lógica da organização do serviço, que dificultava a localização dos prontuários e exigia que um funcionário se prontificasse a encontrá-los, o que implicava disponibilização do seu tempo de serviço para realizar tal tarefa. Pensou-se então em averiguar os prontuários dos pacientes que sofreram reinternações. No entanto, verificou-se que nos registros dos pacientes que passaram pela alta assistida havia apenas dois casos de reinternação, o que reduziria muito o número de prontuários a ser analisados e apontaria um bom resultado do Projeto de Alta-Assistida, tendo em vista o baixíssimo percentual de reinternação dos pacientes submetidos à proposta. Diante disso, optouse por investigar os prontuários dos ex-internos citados mais de uma vez no livro de registro, ou seja, daqueles que tiveram mais de um contato com o profissional de referência no hospital, indicando um acompanhamento continuado, posteriormente à alta. Além disso, esse critério também incluía os dois casos de pacientes reincidentes registrados no projeto. Desta forma, resultou num número de dez prontuários a serem observados. Nessa etapa, foram registrados aspectos como idade, número de internações, data da última internação, data da última alta, procedência, diagnóstico, medicamento utilizado e histórico do paciente.

Por fim, foram realizadas quatro entrevistas com funcionários, sendo duas assistentes sociais, uma psicóloga e uma psiquiatra que ocupava o cargo de diretora técnica do HJM na época em que surgiu o projeto.

\section{Resultados da pesquisa}

Os registros do livro de Alta-Assistida foram organizados em uma tabela (ver Apêndice) para melhor visualização e compreensão dos dados. Constata-se que desde sua implantação, no ano de 2005 até o último registro no livro de AltaAssistida referente a dezembro de 2007, foram contabilizados 97 relatos de acompanhamentos para um total de 73 pacientes (20 mulheres e 53 homens). Observou-se que nos três anos de funcionamento do projeto ocorreram 19 registros em 2005, 57 em 2006 e 23 no ano de 2007. Com isso, nota-se que houve queda considerável no número de registros de 2006 para 2007, a qual pode estar relacionada à grande demanda de atividades e, por consequência, à falta de tempo para o registro, além da mudança na direção técnica que deixou de estimular e cobrar a realização das altas-assistidas. 
Dentre os serviços mais citados estão o CAPS, o PSF, a Secretaria Municipal de Saúde, a Secretaria de Ação Social e postos de saúde. Constatou-se também que esses serviços eram quase todos de cidades do interior do Estado do Rio Grande do Norte $(82,2 \%)$, sendo apenas nove deles $(12,3 \%)$ referentes à capital do estado e os restantes $(0,6 \%)$, de outros estados nordestinos (Paraíba, Ceará e Alagoas). De todos os relatos referentes à receptividade desses serviços frente ao portador de transtorno mental, ou seja, a maneira como o paciente foi acolhido, foi detectado apenas um caso no qual tal recepção não foi satisfatória. Este é o caso da paciente MDN (as iniciais são usadas a fim de preservar a identidade do sujeito e o sigilo ético diante de sua história de vida). Relatou-se no livro de registro da AA que a equipe do hospital realizou visita domiciliar no município da paciente. Nessa visita, foram contatados a Secretaria Municipal de Saúde e o CAPS da cidade. Ambos os serviços colocaram dificuldades para a acolhida da paciente, mas nos relatos não foram especificados a origem nem o tipo de dificuldade colocada.

Ainda em relação aos registros dos acompanhamentos, verificaram-se algumas falhas, como por exemplo, o fato de alguns deles terem sido relatados sem o preenchimento de todas as informações que o livro solicitava. Porém, o que mais impressionou foi a informação de que somente dez usuários (13,7\%) tiveram seus acompanhamentos registrados mais de uma vez no livro da alta-assistida, evidenciando o baixo percentual de pacientes que receberam acompanhamento continuado com retorno da equipe após a alta.

Recorrendo aos prontuários desses pacientes, notou-se que oito eram do sexo masculino e apenas dois do sexo feminino. As primeiras internações ocorreram quando eles tinham idades entre 14 e 31 anos e as últimas reincidências, antes da participação no projeto, foram situadas nos anos de 2006 e 2007. As altas dos pacientes se estabeleceram nesse mesmo período, e as idades dos ex-internos variavam entre 20 e 36 anos. Nenhum deles procedia da capital do Rio Grande do Norte, sendo oito do interior do estado e os outros dois de cidades do interior do Ceará. Seis pacientes haviam passado pela experiência de outras internações, todas no HJM. Também para seis deles foi detectado que o número de reinternaçôes era igual ou superior a oito, chegando, em um dos casos, ao significativo total de 21 reinternações. No entanto, por meio dos prontuários desses pacientes, constatou-se a existência de outros casos de internação fora do hospital referido, sendo duas em hospitais psiquiátricos do Ceará, uma na Casa de Saúde Natal e uma no hospital de custódia. 
Dos dez pacientes submetidos a AA, apenas um havia morado no HJM por 17 anos. Depois que saiu de alta, só se reinternou mais uma vez, num hospital psiquiátrico do Ceará. Os familiares relataram para a equipe responsável pela altaassistida do paciente que essa reinternação foi fruto de uma "agitação" do mesmo, porém não deram maiores detalhes do ocorrido. Após essa reinternação, o paciente voltou ao convívio social e não houve outros casos de internação. Alguns profissionais da equipe responsável por sua enfermaria afirmam que de vez em quando procuram informações sobre ele, e pelo que têm notícia, o paciente está bem, continuando o tratamento em sua cidade e morando com sua família. O prontuário desse paciente foi remetido para sua cidade natal após a alta e não foi devolvido ao HJM.

Em relação ao tempo passado no hospital durante a última internação, constatou-se: de 23 dias a três meses para cinco pacientes; de seis a dez meses para dois pacientes e de mais de um ano para um. Esses dados indicam que a meta estabelecida pelo Ministério da Saúde, de manter um tempo de internação médio de 18 a 30 dias, não vem se concretizando.

Por meio dos dados colhidos no livro de registro dos pacientes submetidos a AA, percebeu-se que a dinâmica dos acompanhamentos se dava pelo contato telefônico e alguns poucos casos por visitas residenciais. Na maioria dos casos $(86,3 \%)$, o trabalho do hospital foi caracterizado por um único contato com os familiares e/ou com o serviço que iria receber o paciente, o que abre margem para o questionamento: é suficiente a realização de um único contato telefônico para se alcançar os objetivos do projeto, como ter a garantia da continuidade do tratamento e redução do número de reinternações?

Quanto ao histórico dos portadores de transtornos mentais, evidenciou-se, em relação aos familiares, que a responsabilidade pelo cuidado do paciente fica a cargo sobretudo da mãe do PTM. Essa constatação, como bem lembram Lima Junior e Velôso (2007), faz referência ao modelo familiar vigente, no qual o pai é responsável pelo sustento familiar, representando o poder econômico-financeiro e a mãe tem a função de cuidar da casa e da criação e educação dos filhos. Autores como Severo et al. (2007) destacam que o movimento da Reforma Psiquiátrica estimula uma retomada da responsabilidade dos familiares no cuidado com o portador de transtorno mental. No entanto, os familiares, conforme observado no livro de registro, falam da impossibilidade de cuidar do paciente, do medo e da insegurança no convívio com o mesmo, sentimentos responsáveis pela rejeição que os pacientes 
sofrem quando saem do hospital. Ou seja, os familiares não se consideram aptos para cuidar, não conhecem os recursos terapêuticos, não encontram suporte na rede de saúde mental, o que os faz vivenciar uma sobrecarga emocional e financeira muito grande. Essa situação favorece a manutenção do modelo biomédico predominantemente medicamentoso e focado na hospitalização do PTM, sendo esta, na maioria das vezes, involuntária, pois representa um alívio para muitas famílias.

Entende-se, portanto, que o trabalho de acompanhar pacientes em alta hospitalar requer algumas estratégias, sendo duas delas muito importantes: o trabalho com as famílias e a articulação com serviços de saúde e de assistência social, a fim de manter o paciente no território e evitar as reinternações. Quando esses contatos e pactuações falham, ocorrem situações como a relatada a seguir.

JP, um dos casos reinternados durante a realização da AA, nasceu de uma relação incestuosa (pai engravidou a filha), foi adotado por outra família e ficou ciente de sua verdadeira história aos oito anos de idade. Começou a apresentar problemas ainda na infância; mesmo assim, freqüentou a escola e conseguiu se alfabetizar. Sua primeira crise se manifestou aos 14 anos, quando a família passava por dificuldades financeiras. Com a primeira crise, o paciente foi internado na Casa de Saúde Natal. Ao receber alta, passou três anos sem se reinternar, sendo atendido pelo CAPS do seu município. Com a manifestação de uma crise agressiva, o próprio serviço substitutivo encaminhou JP para o HJM. Durante sua estadia no HJM foi relatada, tanto pelo paciente quanto por sua mãe, a insatisfação com o trabalho desenvolvido no CAPS que JP freqüentava. Porém, quando este saiu de alta, foi novamente encaminhado para o serviço que já havia dito ser incompatível com suas necessidades. Isso evidencia a falta de cuidado da equipe do HJM com o projeto terapêutico desse paciente que não comportava a volta ao CAPS, caso não fosse proposto um redirecionamento da sua condução. Deveriam ter sido pensadas outras alternativas de cuidado, como por exemplo, uma articulação com as equipes de PSF e a oferta de matriciamento às mesmas.

Esse relato aponta para a importância dos prontuários como meio de obtenção de dados imprescindíveis ao processo de alta assistida. No entanto, é importante sinalizar que a forma como os prontuários vêm sendo preenchidos não facilita a utilização desse instrumento no processo de avaliação e planejamento da alta. A equipe multiprofissional responsável por esse preenchimento realiza relatos pontuais do cotidiano do paciente, levando em conta apenas sua área de atuação. Sendo 
assim, o psicólogo comenta sobre a orientação psíquica do paciente; a enfermeira, sobre o medicamento que foi ministrado; o nutricionista, sobre a dieta, etc. Observou-se também que os registros não obedeciam a uma sistemática, podendo ser encontrados relatos de todos os profissionais da equipe no mesmo dia, a nãoexistência de relatos por mais de uma semana, ou mesmo relatos repetidos por profissionais de turnos diferentes. Este último fato serve para evidenciar que nem os membros da equipe leem o que os outros profissionais escrevem. Outro ponto que nos chamou atenção foi a desorganização dos prontuários. Como muitos dos internos sofrem reinternações ou passam muito tempo no hospital, seus prontuários têm acúmulo de informações, tornando-se volumosos. Como não há organização, verificou-se uma desordem cronológica nas folhas do prontuário, tornando-se mais um obstáculo para a utilização desse instrumento no planejamento da alta.

Em outras palavras, verificou-se falta de organização e sistematização nos registros, o que dá uma característica absolutamente burocrática a esse instrumento, que tem uma potencialidade de orientar as ações da equipe, mas que vem sendo negligenciado nesse aspecto. Observou-se também que essa desorganização do conteúdo do prontuário reflete a fragmentação das ações da equipe técnica que promove ações individualizadas. Essa fragmentação dificulta a visão integral do paciente, da sua história, bem como o estabelecimento de um projeto terapêutico que leve em conta suas características, inserção social e familiar.

Apesar de não haver dados suficientes para ampliar a discussão acerca da reinternação no HJM, é possível perceber que o projeto de alta-assistida não alcançou um dos seus principais objetivos: a redução no número de reinternações. Considera-se que tal situação é efeito de uma complexa rede de fatores e não apenas dos problemas vividos unicamente por tal projeto. Dentre esses fatores, destacam-se a precariedade da assistência dentro do HJM, a ausência de uma rede articulada para dar suporte aos serviços substitutivos, a fragilidade do usuário, as dificuldades no enfrentamento de aspectos da vida social e, dentre esses, o difícil relacionamento familiar.

\section{A proposta da AA segundo a equipe técnica}

As entrevistas possibilitaram observar que o Projeto de AA havia sido pensado primeiramente pela então diretora técnica. Esta teve como inspiração para sua realização um livro cujo tema era "o transtorno mental e a família". Para essa 
profissional, a AA não deveria ser encarada como um projeto, mas como uma forma de se trabalhar, de comprometer a família, a sociedade e os dispositivos da rede no município do paciente. Desta forma, a AA é percebida como um excelente mecanismo no combate ao alto índice de reinternação observado dentro do HJM.

Antes mesmo de o projeto ser adotado pela instituição, práticas parecidas já eram desenvolvidas de forma espontânea e pontual por algumas equipes do hospital. A institucionalização do projeto serviu apenas para encorajar as realizaçóes das altas assistidas diariamente e por todas as equipes do hospital, bem como para cobrar o registro dos casos no livro da AA e no prontuário dos pacientes, além da apresentação dos casos acompanhados nas reuniōes técnicas quinzenais. Essas medidas tentavam comprometer os profissionais com o processo. No entanto, percebeu-se que, com a disponibilidade de verbas para diárias em outros municípios, houve descaso com os ex-internos da capital. Desse modo, houve uma desvirtuação do sentido do projeto, já que as altas passaram a acontecer muito mais em função do "passeio", pois estavam priorizando os pacientes do interior do $\mathrm{RN}$, do que realmente para a realização do acompanhamento. Deste modo, os registros e as apresentaçôes nas reuniões apareciam apenas como forma de justificar as diárias.

$\mathrm{O}$ fato acima evidencia o descaso e o não-compromisso com os usuários por parte de alguns profissionais que fazem parte de equipes que realizam a AA, bem como uma postura utilitarista, na medida em que eles acompanham os pacientes do interior em função do recebimento de diárias, evidenciando o mau uso do dinheiro público.

As proponentes do projeto relataram não concordar com o mecanismo de acompanhamento que se estabeleceu: um telefonema ou uma visita domiciliar, entendidos como cuidado continuado. Segundo a psicóloga entrevistada, "nada se sobrepõe ao contato pessoal com a comunidade, a família, os gestores e a própria justiça”. De acordo com as profissionais, as visitas deveriam ser mais constantes, e apenas nos casos de pacientes fora da capital deveria optar-se por, após a primeira visita, continuar o cuidado através do contato telefônico. Dessa forma, seria economizado o valor das diárias, já que estas estavam sendo utilizadas sem critério.

Sinalizou-se também que a maneira de realizar o acompanhamento deveria levar em consideração a dinâmica familiar dos usuários, não podendo ser realizada da mesma forma para um paciente com grande rejeição familiar e outro que tenha familiares dedicados com conhecimento a respeito do transtorno mental, além de 
apoio por parte da rede de serviços municipais. Destacou-se a importância de um acompanhamento mais presente nos casos de rejeição familiar, o que exigiria várias visitas domiciliares, pois seria necessário o trabalho com a família do paciente.

Uma das assistentes sociais, ao ser indagada sobre a ausência de uma sistemática para o retorno dos pacientes, fez uma ressalva interessante: afirmou ser importante o acompanhamento continuado, mas atentou para o fato de que não basta o hospital psiquiátrico tomar a frente do cuidado do paciente fora da instituição. Para ela, esse vínculo acarreta a acomodação do município e deixa o paciente sempre dependente do hospital, sendo difícil para ele entender que a AA não tem relação com o atendimento médico. Argumentou citando o caso de um paciente que exigia a renovação da receita médica, acreditando ser essa sua atribuição enquanto realizava a AA. Concluiu que achava importante um retorno, mas se deveria deixar claro o limite da atuação.

É interessante ressaltar a percepção dessa assistente social, pois ela lança olhares para todos os ângulos de um projeto, que a princípio não deveria existir, mas que, pela desassistência e defasagem dos serviços substitutivos da rede extra-hospitalar, torna-se de extrema importância como forma de tentar evitar as reinternações. No entanto, deve-se apontar sua função paliativa, já que a AA tenta resolver problemas deixados por outros sistemas que não dão conta do problema, como a Secretaria de Saúde do Município, PSF, CAPS, dentre outros.

Nota-se, portanto, que por um lado, o projeto de AA só tem razão de existir pela ausência de suporte no município para atender à demanda de pacientes que deveriam ser assistidos na comunidade e, dessa forma, seria seu objetivo último deixar de existir, quando fosse possível contar com a rede extra-hospitalar. Por outro lado, deve-se observar que também é dever dos funcionários do hospital psiquiátrico promover a desinstitucionalização e, na medida em que tentam engajar e assegurar o tratamento do paciento no seio da sua comunidade, contribuem para isso.

As entrevistadas também explicitaram o motivo para o grande número de AA que, mesmo sendo realizadas, não eram registradas. Para elas, esse problema era fruto de uma sobrecarga de trabalho dos profissionais que tinham que realizar o acompanhamento sem deixar de dar conta de suas funções no próprio hospital. Dessa forma, muitas vezes a alta se realizava, mas não era registrada em função do tempo que essa prática necessitava. Outro fator que também serviu para justificar essa falta de registro foi a não-utilização desse instrumento como forma de nortear 
o trabalho de outras altas; ou seja, os profissionais apenas relatam o acompanhamento no livro de registro e nos prontuários, mas nunca esses documentos são reutilizados, fato que desanima e desmotiva registros futuros.

A sobrecarga profissional está relacionada a outras atividades que são prioridades enquanto atribuições, como as portas de entrada dos pacientes que são a sala de serviço social e o pronto-socorro, sobrando pouco tempo para dedicar à enfermaria e, por conseguinte, ao projeto da AA. Além da sobrecarga profissional, outro fator que contribuiu para as falhas observadas no projeto foi a mudança na direção técnica. O novo diretor deixou de motivar a realização das AA e a partir disso não só os registros, mas também os acompanhamentos começaram a ser realizados de forma esporádica.

Outro ponto observado durante as entrevistas foi o claro desânimo dos profissionais diante da ausência de reconhecimento por parte da instituição. A psicóloga coloca que escreveu sobre um dos casos de alta assistida que realizou e que teve excelente resultado, pois o paciente que antes sempre se internava conseguiu se estabelecer no seu município, tanto em relação ao tratamento quanto à ocupação, explorou um desejo de se vendedor e conseguiu realizar esse projeto de vida. Seu trabalho foi selecionado para ser apresentado na Expogest, em Brasília. Ela fez, com ajuda de colaboradores, um cordel contando a história desse caso e levou. Lá, fez divulgação desse trabalho, realizou trocas importantes para assistência, mas lamenta muito o fato de os funcionários do HJM sequer terem tido interesse pelo caso e pelo trabalho que foi feito a partir dele.

Esse aspecto merece se levado em consideração, uma vez que o profissional, ao não receber estímulos da própria instituição de que faz parte, desmotiva-se e perde o entusiasmo para realizar sua prática com empenho e dedicação. É preciso apoio do corpo da direção. É necessário que leiam, estudem o projeto para saberem a importância dele e se envolvam.

Ao serem analisadas de forma ampla, foi possível detectar nas entrevistas que, apesar das falhas apontadas, alguns ganhos, no sentido de implementação da AA, puderam ser observados: a preocupação das equipes responsáveis pela alta, no sentido de conscientizar os gestores do município em relação à Reforma Psiquiátrica e promover o interesse deste para providenciar a assistência aos pacientes. Para atingir esse objetivo, alguns componentes das equipes usaram como estratégias a apresentação de fôlderes sobre implantação de CAPS, cópias 
de portarias e projetos, bem como demonstrativos estatísticos das internações provenientes do município visitado; a constatação de que, nos casos em que o acompanhamento se desenvolveu de forma contínua e sistemática, não ocorreu reinternação dos pacientes; a conscientização, por parte dos proponentes do projeto, de que "a semente foi plantada", necessitando, contudo, de uma reavaliação da prática para evitar que as mesmas falhas continuassem a ocorrer; a percepção, pelos proponentes do projeto, da importância de se ter uma continuidade do trabalho apesar da mudança na diretoria técnica.

Ao término das entrevistas, pediu-se que as entrevistadas citassem pelo menos um caso de uma alta assistida bem-sucedida e uma malsucedida. Referiram-se, para os casos bem-sucedidos, os pacientes que não se reinternaram e que saíram do hospital com algum benefício social e inseridos em algum serviço substitutivo em sua comunidade.

Para melhor ilustração, citamos o caso de um paciente de João Câmara (interior do estado) que se reinternava constantemente. Foi feito um trabalho no seu município, com seu cuidador, além de providenciar seus direitos assistenciais, como a aposentadoria. A equipe continuou fazendo contato com ele por mais de seis meses, e o próprio cuidador também ligava ou ia até o HJM para dar notícia. Atualmente, ele trabalha junto com seu cuidador, frequenta o CAPS e nunca mais se internou.

Em relação aos casos malsucedidos, a equipe aponta a presença de necessidades que extrapolam o alcance dos profissionais, o que impede a transformação da situação. Cita-se como exemplo o seguinte caso: um jovem que morava numa cidade litorânea e que tinha muitos problemas com tráfico de drogas. Chegavam várias embarcaçóes com drogas, o que facilitava o uso; considera-se que foi um caso que ultrapassou o alcance da equipe. Foram até o município, tentaram fazer um trabalho de conscientização, mas não houve sucesso. O paciente continua até hoje sendo constantemente reinternado.

\section{Considerações finais}

Em geral, observou-se que a maioria dos contatos realizados se restringe a uma ligação, ou uma visita domiciliar, evidenciando falha no processo, pois não há como se assegurar a continuidade do tratamento, uma vez que a equipe do HJM que acompanha o paciente transfere a responsabilidade para o município em que 
mora. Não há sistematização quanto ao retorno do paciente, procurando-se, por exemplo, saber se ele está sendo assistido, se está frequentando um serviço substitutivo, se tem a medicação necessária e está fazendo o uso adequado.

Após análise dos resultados, agendou-se um grupo focal com a diretora geral do HJM, para o qual que foram convidados os profissionais de diferentes equipes, a fim de realizar uma devolução, expondo o que foi feito na pesquisa e, principalmente, apontar os aspectos relevantes para promover transformação na atenção dada pelo HJM a seus pacientes. Pontua-se, no entanto, que apesar de a direção do HJM ter fornecido total abertura para o desenvolvimento da pesquisa e haver interesse pelo trabalho, tanto da direção quanto de alguns profissionais, a realização do grupo focal foi inviabilizada. O grupo foi agendado quatro vezes, mas em nenhuma delas teve público para que fosse possibilitada a troca, apenas na primeira vez em que foi marcado compareceram quatro funcionárias do HJM, exatamente aquelas que se mostraram mais interessadas e de certo modo já são comprometidas com o trabalho. Assim, a proposta de devolução com fins de incitar um movimento gerador e potencializador de transformação não ocorreu.

Como conclusão, indicam-se alguns aspectos relevantes e norteadores que podem contribuir para a melhoria da atenção ao portador de transtorno mental pelo HJM: incentivo da direção do HJM para realização das altas assistidas; ter espaço reservado para troca de experiências entre os profissionais, a para que se possa compartilhar o que está sendo feito para tentar melhorar a qualidade da atenção dada e pensar estratégias possíveis; ter uma sistemática em relação ao retorno ao paciente, o que garantiria continuidade no acompanhamento que, dependendo do caso, pode ser por telefone ou através de visita domiciliar.

E ainda: disseminar a importância da prática da alta assistida dentro do hospital para que esta possa se tornar uma prática adotada pela instituição, como parte integrante das atribuições da equipe e não uma atividade extra que pode ou não ser realizada; organizar a rotina da enfermaria entre os profissionais que compõem a equipe multidisciplinar, possibilitando a realização das altas assistidas; realizar escuta qualificada ao paciente; organizar e sistematizar os registros nos prontuários para possibilitar o acesso a eles, quando necessário, para orientar a equipe na realização da alta assistida; dar atenção às informações contidas no prontuário, levando em consideração aspectos relevantes da história do paciente, suas características, inserção social e familiar que podem contribuir para elaborar o 
projeto terapêutico individual e traçar a estratégia do seu acompanhamento, pois cada caso é singular e, assim, ter-se-ia uma visão integral do paciente.

Por fim, selecionar os casos necessitados para realizarem a alta assistida, estabelecendo-se critérios para isso, como o alto número de reinternação ou um histórico familiar delicado de rejeição do paciente; promover o trabalho com as famílias e a articulação com serviços de saúde e de assistência social, a fim de assegurar o tratamento do paciente em seu território e tentar evitar as reinternaçóes; analisar a situação do município do paciente quanto aos serviços que oferecem para atendê-lo; divulgar, nos municípios, as possibilidades e responsabilidades desses para oferecerem atenção ao portador de transtorno mental e comprometer a família e a sociedade no tratamento do paciente, tentando romper com os preconceitos e com o estigma que cerca a doença mental e dificulta a inserção do paciente em sua comunidade.

\section{Referências}

DELGADO, Pedro G. O tratamento a partir da reforma psiquiátrica. In: QUINET, A. (Org.). Psicanálise e psiquiatria: controvérsias e Convergências. Rio de Janeiro: Marca D’Água, 2001.

FIORATI, Regina C. Acompanhamento terapêutico: uma estratégia terapêutica em uma unidade de internação psiquiátrica. Dissertação (mestrado) - Universidade de São Paulo, Riberão Preto, 2006. LIMA JÚNIOR, Joel; VELÔSO, Thelma M. G. Convivendo com a loucura: as representações sociais de familiares de usuários de instituições psiquiátricas. Vivência, Natal, v. 10, n. 32, p. 163-171, 2007.

BRASIL. Ministério da Saúde. Programa de Volta para Casa. Disponível em: <http:// pvc.datasus.gov.br> Acesso em: 27 nov. 2006.

BRASIL. Ministério da Saúde. Cadastro Nacional de Estabelecimentos de Saúde. Disponível em: http://cnes.datasus.gov.br/Exibe_Ficha_Estabelecimento.asp?VCo_Unidade=2408102408260 Acesso em 16 jun. 2009.

BRASIL. Ministério da Saúde. Distribuição dos leitos psiquiátricos SUS por UF e hospitais Psiquiátricos e indicador leitos por 1.000 hab. Disponível em: http://portal.saude.gov.br/portal/arquivos/pdf/ leitos_psiquiatricos_uf.pdf Acesso em 16 jun. 2009b.

BRASIL. Ministério da Saúde. Serviços Residenciais Terapêuticos implantados e em processo de implantação, por UF. Disponível em: http://portal.saude.gov.br/portal/arquivos/pdf/ servicos_residenciais_terapeuticos_por_uf.pdf Acesso em: 16 jun 2009c. 
BRASIL. Ministério da Saúde. Número de beneficiários do Programa de Volta para Casa por UF. Disponível em: http://portal.saude.gov.br/portal/arquivos/pdf/dados_de_volta_para_casa.pdf Acesso em: 16 jun 2009d.

OLIVEIRA, F. B.; FORTUNATO, M. L. Reabilitação psicossocial na perspectiva da reforma psiquiátrica. Vivência, Natal, v. 10, n. 32, p. 155-161.7, 2001.

SEVERO, Ana Kalliny de S. et al. A experiência de familiares no cuidado em saúde mental. Arq. Bras. Psicol, Rio de Janeiro, v. 59, n. 2, 2007. Disponível em: http://pepsic.bvs-psi.org.br/ scielo.php?script=sci_arttext\&pid=S1809-52672007000200005\&lng=pt\&nrm=is. Acesso em: 8 set. 2008. 


\section{APÊNDICE - Tabela de Registros do Projeto Alta-Assistida}

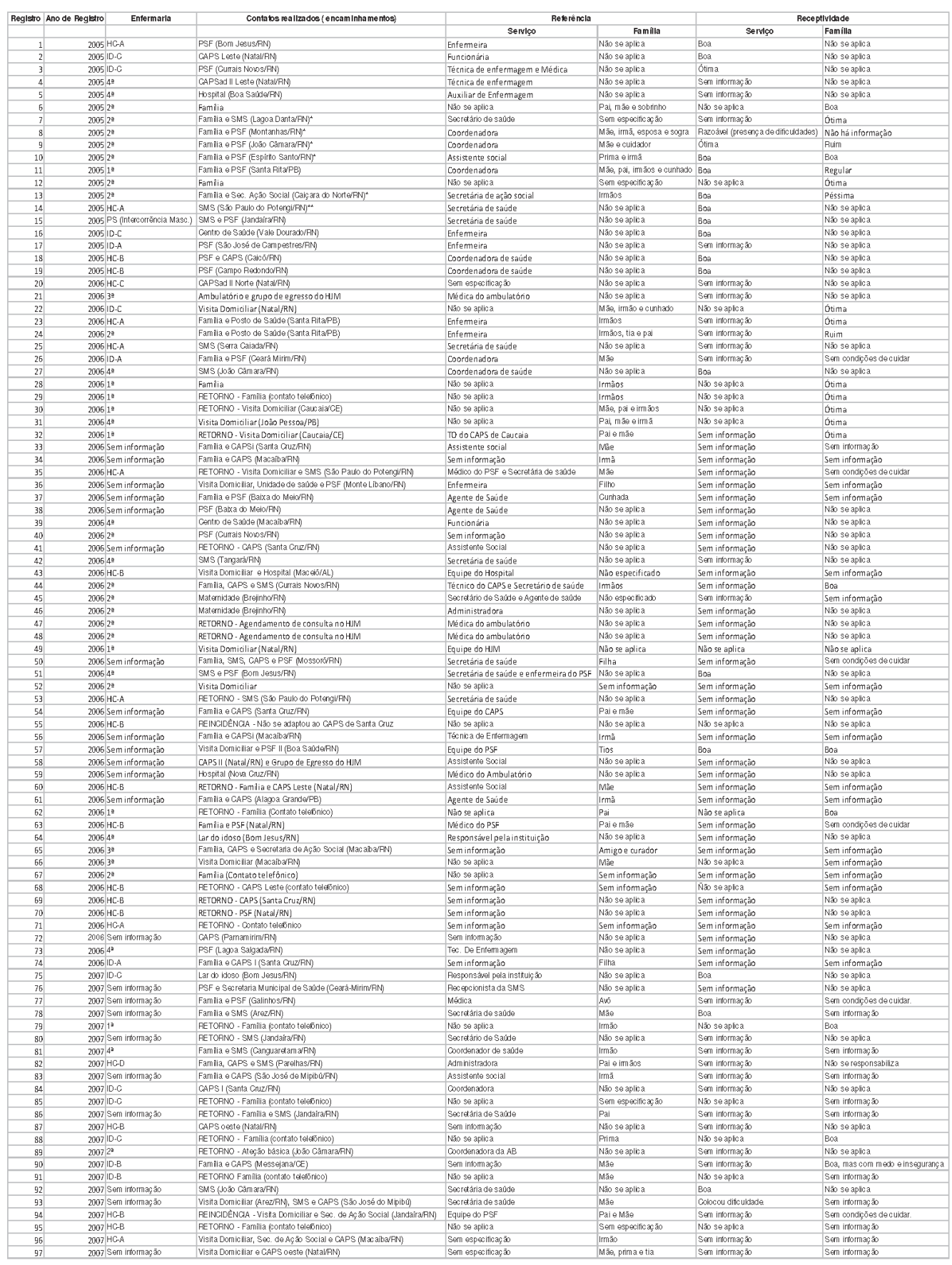

Nota

${ }^{1}$ Este projeto contou com a ajuda financeira do CNPq. 
Assisted-Discharge of users of a psychiatric hospital: a proposal under review One of the current obstacles to the psychiatric reform is the absence of an agile, flexible and problem-solving welfare network. The proposed removal of users from the hospital in a planned and assisted is a key strategy in the process of deinstitutionalization, in order to avoid the phenomenon of so marked rehospitalization. This situation is related to the lack of a network of care outside hospitals, as well as supporting and monitoring of the user by the technical team in partnership with families. On this basis, there was an investigation into a psychiatric hospital in the city of Natal, to evaluate the process of deployment and operation of the Project for Assisted Discharge currently in progress at that institution. This work discusses the results of this research.

> Key words: Mental Health; Psychiatric Reform; Psychiatric Hospital; Assisted-Discharge; Social Reintegration. 